\title{
First Crio-extraction of Cherry Pit after Aspiration
}

Gómez López A*, García Luján R ,Valipour A and Miguel Poch E

Endoscopic Unit, Hospital Universitario 12 de Octubre, Madrid, Spain

“Corresponding author: Gómez López A, Paseo de las Delicias 65, bloque B, escalera 1, Madrid, España, Tel: 0034663041414; E-mail: antolinagl@hotmail.com Received date: April 8, 2016; Accepted date: May 10, 2016; Published date: May 16, 2016

Copyright: @2016 López AG, et al. This is an open-access article distributed under the terms of the Creative Commons Attribution License, which permits unrestricted use, distribution, and reproduction in any medium, provided the original author and source are credited.

\begin{abstract}
Introduction: Vegetable foreign bodies (FB) are most commonly aspirated in children, these are very dangerous as most of them are hygroscopic, they swell up within a few days causing blockage of the lumen of the bronchus and retention of secretion distal to it.

Method: We report on a $75 \mathrm{yr}$ old patient who aspirated a cherry pit one month prior to clinical presentation. He originally presented with cough and a right lower lobe infiltrate on x-ray. The patient underwent therapeutic videobronchoscopy via the oral route, a cherry pit was detected at the distal end of the bronchus intermedius with signs of local inflammation.

Result: We used saline rising and a flexible cryoprobe and it was activated for $15 \mathrm{~s}$ which resulted into a solid contact with the FB and immediate removal without complications.

Conclusion: We have found that by using flexible cryoprobe through video bronchoscopy is possible remove a cherry pit under conscious sedation, which should be considered as a therapeutic option.
\end{abstract}

Keywords: Cryoextraction; Cherry pit; Broncho-aspiration; Foreign bodies

\section{Introduction}

Vegetable foreign bodies (FB) are most commonly aspirated in children, these are very dangerous as most of them are hygroscopic, they swell up within a few days causing blockage of the lumen of the bronchus and retention of secretion distal to it [1].

Using a lung model, Fruchter and Kramer [2] explored the cryoadhesive properties of various organic and inorganic commonly aspirated objects. They observed substantial differences in cryoadhesion time between metallic (i.e., paper clip, hair pin...) objects with $5 \mathrm{~s}$ and organic objetcts, with lower adhesion properties, such an almond or nuts (neither with $10 \mathrm{~s}$ of cryoprobe application). In our case, just only above $10 \mathrm{~s}$ was achieve to remove the FB.

Here we report on a $75 \mathrm{yr}$ old patient who aspirated a cherry pit one month prior to clinical presentation. The cherry pit was successfully removed with a cryoprobe and the patient discharged within few hours after the procedure.

\section{Case Report}

A $75 \mathrm{yr}$ old patient, carrier a pacemaker, was referred to our hospital from another institution for endoscopic foreign body (FB) removal. $\mathrm{He}$ originally presented with cough and a right lower lobe infiltrate on $\mathrm{x}$ ray without fever, dysnea or chest pain. The patient had not neurological problem or previous known bronchoaspiration episodes.

A CT scan was performed (Figure 1) suggesting a FB aspiration. On further exploration, the patient recalled an episode of potential food aspiration while eating cherries.
The patient underwent therapeutic videobronchoscopy via the oral route under conscious sedation (Propofol). A cherry pit was detected at the distal end of the bronchus intermedius with signs of local inflammation and FB reaction (Figure 1).

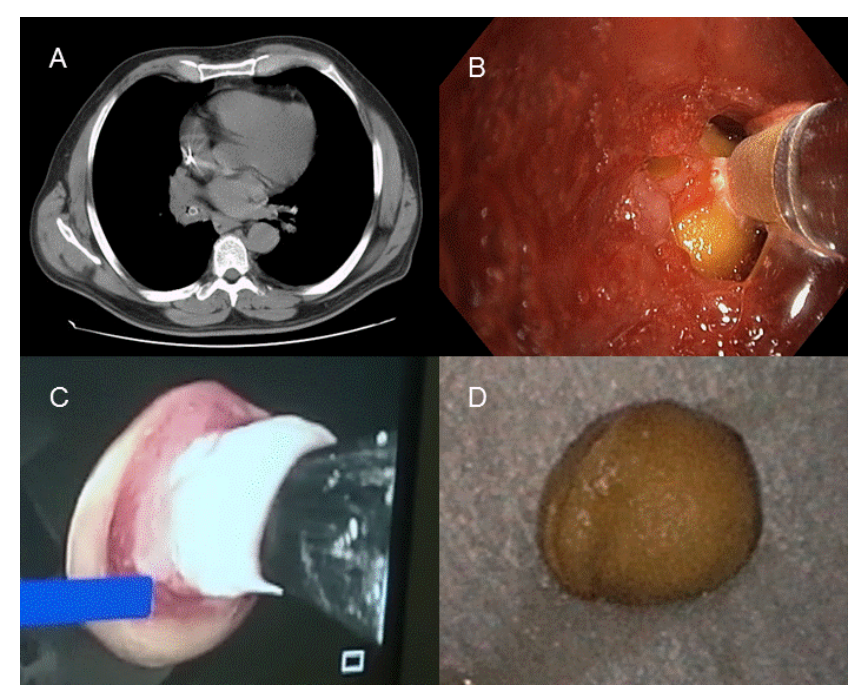

Figure 1: Pictures case report A) Scanner with cherry pit in bronchus intermedius. B) Initiating freezing between cherry pit and cryosonde. C) Cryoextraction. D) Cherry pit.

We used saline rising, which helped us to clean the surface and some purulent secretions around the $\mathrm{FB}$, a flexible cryoprobe $(1.9 \mathrm{~mm}$, Erbokryo) was inserted into the working channel of the bronchoscope 
Citation: López AG, Luján RG, Valipour A, Poch EM (2016) First Crio-extraction of Cherry Pit after Aspiration. Lung Dis Treat 2: 106. doi:

Page 2 of 2

and the put in contact with the cherry pit. The cryoprobe was activated for $15 \mathrm{~s}$ (after twice attempts with less seconds), which resulted into a solid contact with the FB and immediate removal (Figure 1) all in block. A few hours later the patient was referred to his house with antimicrobial therapy for 10 days.

\section{Discussion}

Compared with children, FB aspiration is rather rare in adults. The incidence of FB aspiration in adult is $<0.4 \%$, Blanco et al describe 32 aspiration in 9781 procedures, $78 \%$ of them inorganic material and second position dental materials [3]. Nevertheless, an interesting study in adults about vegetable FB around eating habits have reported and removed with flexible bronchoscopy: Lin et al. [4] studied in Republic of China a fondness of eating peppery food with cayenne. Nguyen et al. [5] showed that in Vietnamese adults the most frequently found aspirated FB is the sapote pit, from a locally grown sweet fruit (Casimiroa edulis).

In addition to its properties of taking central or peripheral biopsy material, the flexible cryoprobe can also be used for FB removal. Freezing of the cryoprobe's tip is achieved with the Joules-Thomson effect.

Schumann published a gold tooth implant removed easily with cryoprobe after ice formation [6]. Using a lung model, Fruchter and Kramer [2] explored the cryoadhesive properties of various organic and inorganic commonly aspirated objects. They observed substantial differences in cryoadhesion time between metallic (i.e., paper clip, hair pin, etc.) objects with $5 \mathrm{~s}$ and organic objetcts, with lower adhesion properties, such an almond or nuts (neither with $10 \mathrm{~s}$ of cryoprobe application). In our case, just only above $10 \mathrm{~s}$ was achieve to remove the FB.

We would like to focus on the possibility of this kind of method to extract specific foreign bodies in various scenarios of $\mathrm{FB}$ aspiration and the possibility of it in elderly people using this technique without the need for other invasive procedures.

\section{References}

1. Monoj M, Ranjal P (2011) Foreign Body Aspiration: Demographic Trends and Foreign Bodies Posing a Risk. Indian J Otolaryngol Head Neck Surg 63: 313-316.

2. Fruchter O, Kramer MR (2015) Retrieval of various aspirated foreign bodies by flexible cryoprobe: in vitro feasibility study. Clin Respir J 9: 176-179.

3. Blanco M, Fernández-Villar A, Rivo JE, Leiro V, García-Fontán E, et al. (2009) Extraction of airway foreign bodies in adults: Experience from 1987-2008. ICVTS 9: 402-405.

4. Lin L, Wang Y, Zha X, Tang F, Lv L, et al. (2014) Cayenne aspiration: an unusual type of lower airway foreign-body aspiration. Clinical Interventions in Aging 9: 2019-2025.

5. Nguyen LH, Nguyen DH, Tran TN, Nguyen PT, Thi QH, et al. (2010) Endobronchial foreign bodies in Vietnamese adults are related to eating habits. Respirology 15: 491-494.

6. Schumann C, Kropf C, Rüdiger S, Wibmer T, Stoiber KM, et al. (2010) Removal of an Aspirated Foreign Body With a Flexible Cryoprobe. Respiratory Care 55:1097-1099. 